\title{
Prevalence of and factors associated with obesity among Pakistani schoolchildren: a school-based, cross-sectional study
}

J. Ahmed, ${ }^{7}$ A. Laghari, ${ }^{2}$ M. Naseer ${ }^{3}$ and V. Mehraj ${ }^{4}$

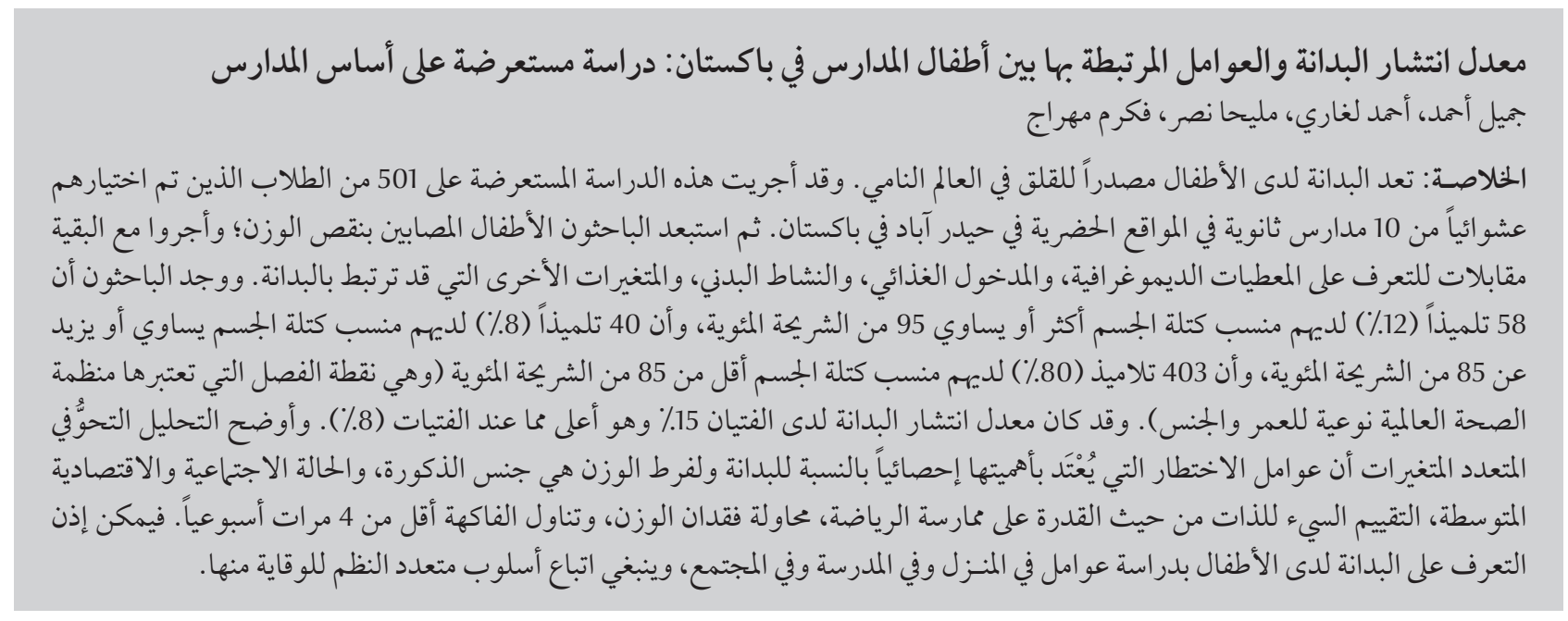

ABSTRACT Childhood obesity is nowadays a concern in the developing world. This cross-sectional study was conducted on 501 randomly selected students from 10 high schools in an urban setting in Hyderabad, Pakistan. Children who were underweight were excluded. Interviews were conducted to determine demographic data, dietary intake, physical activity and other variables that may be associated with obesity. Overall 58 students (12\%) had body mass index $(\mathrm{BMI}) \geq 95$ th percentile, $40(8 \%) \mathrm{BMI} \geq 85$ th percentile and $403(80 \%)$ had $\mathrm{BMI}<85$ th percentile $(\mathrm{WHO}$ age- and sex-specific cut-offs). The prevalence of obesity was higher in boys than girls ( $15 \%$ than $8 \%$ respectively). In multivariate regression analysis significant risk factors for obesity/overweight were male sex, middle socioeconomic status, poor self-rated athletic ability, trying to lose weight and eating fruit $<4$ times per week. Childhood obesity is determined by factors in the home, school and society and a multidisciplinary approach is needed to prevention.

Prévalence de l'obésité chez des élèves pakistanais et facteurs associés : étude transversale en milieu scolaire

RÉSUMÉ Aujourd'hui, l'obésité de l'enfant est devenue une préoccupation dans le monde en développement. La présente étude transversale a été menée auprès de 501 élèves sélectionnés aléatoirement dans dix établissements d'éducation secondaire en milieu urbain à Hyderabad (Pakistan). Les enfants souffrant d'une insuffisance pondérale ont été exclus. Des entretiens ont été effectués afin de déterminer les données démographiques, l'apport alimentaire, l'activité physique ainsi que les autres variables potentiellement associées à l'obésité. Au total, 58 élèves (12\%) avaient un indice de masse corporelle supérieur ou égal au 95e centile, 40 (8\%) avaient un indice de masse corporelle supérieur ou égal au 85e centile et $403(80 \%)$ avaient un indice de masse corporelle inférieur au 85e centile (d'après les seuils par âge et par sexe définis par l'Organisation mondiale de la Santé). La prévalence de l'obésité était plus forte chez les garçons que chez les filles (15\% et $8 \%$ respectivement). À l'analyse de régression multivariée, les facteurs de risque importants pour l'obésité ou le surpoids étaient le sexe masculin, un statut socioéconomique intermédiaire, une aptitude au sport autodéclarée comme médiocre, l'intention de perdre du poids et une consommation de fruits inférieure à quatre fois par semaine. L'obésité de l'enfant est déterminée par des facteurs liés à l'environnement domestique, scolaire et social. Une approche pluridisciplinaire de la prévention est donc requise.

'Department of Research and Development, Health Services Academy, Islamabad, Pakistan (Correspondence to J. Ahmed: jamil.ahmed.dr@gmail.com). ${ }^{2}$ National Tuberculosis Programme, Islamabad, Pakistan. ${ }^{3}$ Department of Community Health Sciences, The Aga Khan University, Karachi,

Pakistan. ${ }^{4}$ Faculté de Médecin, Université de la Méditerranée (Aix-Marseille II), Marseille, France.

Received: 30/10/11; accepted: 21/02/12 


\section{Introduction}

Globally at least 20 million children under the age of 5 years were estimated to be overweight in the year 2005 [1] and studies on childhood obesity show a prevalence of obesity ranging from $5 \%$ to $20 \%$ in various settings [2-4]. Changing dietary patterns, sedentary lifestyles and a decline in physical activity are believed to contribute to the worldwide obesity epidemic among both adults and children. Although the problem of adult obesity has already received some attention in research in Pakistan $[5,6]$, the subject of obesity among children has only recently gained attention [7-10]. Pakistan has an estimated prevalence of childhood obesity between $15 \%$ to $20 \%$ [11]. The proportion of obese and overweight children in Karachi was found to be $6 \%$ and $19 \%$ respectively [9]. Being a low-income country, Pakistan faces the double burden of communicable and noncommunicable diseases and obesity is a major risk factor for the rising epidemic of cardiovascular diseases and diabetes mellitus [12].

Socioeconomic status seems to be a factor in obesity. In developed countries obesity seems to be more common among poorer communities, where family influences on foods eaten and physical activity levels are directly correlated with rising trends of obesity [13]. In Pakistan, however, it was observed that obesity was associated with higher socioeconomic status, whereas among lower socioeconomic status children undernutrition was more likely to be a problem [10]. A high quantity of meat eaten by children is also believed to be associated with childhood obesity and children are increasingly exposed to such foods in urban Pakistan [10]. Other factors that have been implicated are parental obesity and diabetes [14], lack of attachment with parents [15] and genetic and environmental factors [16].
This study was carried out to understand and quantify the factors within the school, home and overall social environment that could be responsible for the growing burden of obesity in our child population. Few studies have been done to ascertain the type and amount of exercise or the types of foods in the home and school environment that could contribute toward an abnormal weight gain in children in the Pakistani context. The study was designed to help formulate recommendations for preventing obesity in an urban setting of a developing country. We specifically aimed to estimate the prevalence of and factors associated with obesity among schoolchildren in classes 6 to 10 of government and private schools in a sub-district of Hyderabad city.

\section{Methods}

\section{Study design and setting}

This was a cross-sectional study, conducted over a 6-month period from 1 January 2008 to 30 June 2009 in an urban sub-district of Hyderabad city (Talukas). According to 1998 census (the most recent census held in Pakistan) the population of Hyderabad was 1166894 , which was estimated to have almost doubled due to rapid urbanization and high population growth.

\section{Sample size}

We calculated the sample size for 2 population proportions using Epi-Info, version 6 . For associated factors $31 \%$ prevalence of mothers of non-obese schoolchildren with low education, $24 \%$ prevalence of non-obese schoolchildren in the upper socioeconomic status and $17 \%$ prevalence of non-obese children of working mothers (expected frequency of disease among nondiseased) were considered [17]. The variable mother's education gave the largest sample of all the independent variables. To determine the association of mother's education with obesity in children we took a confidence level of $95 \%$, power of $80 \%$, the ratio of exposed children (whose mothers are illiterate) to unexposed children (children whose mothers have at least 5 years of education) and the prevalence of obesity among children of educated mothers of $31 \%$ and the sample size was determined as 336. Using a design effect of 1.5 for adjusting for the complex sampling technique the final sample size was estimated to be 504 .

\section{Sampling technique}

Students in classes 6 to 10 in the selected public and private schools were eligible for the study. Children who did not consent and those who were not present on the day of the survey were excluded; in the latter case the next student on the list was recruited. It was determined through the Hyderabad district education office that there were about 212 private and 10 government schools which were eligible for the study. The enrolment was $90 \%$ in private and $10 \%$ in government schools at the start of the survey. However, the male to female enrolment is almost equal in both types of schools. Therefore the sample size of 504 was divided among public and private schools according to the probability proportional to size of students in schools in the city. In the next stage the remainder of the sample was divided among male and female students. Two public and 8 private schools were taken through simple random sampling. Finally, the students were selected from the list of the students from the classes through random sampling.

Informed consent was taken before the interviews, from the parent of each child and the purpose of the survey was conveyed to them. The study was approved by The Aga Khan University ethics review committee.

\section{Data collection tools}

A questionnaire was used to collect data on sociodemographic variables, variables in the school environment 
concerning physical activity of the students, students' self-rated athletic ability, dietary practices at school, parental/ home factors promoting obesity among children and students' dietary intake. For the assessment of the type and quantity of foods routinely eaten, we adapted an adult food frequency questionnaire for children and the respondents were asked to recall their dietary intake of various local foods in the previous week and the frequency of consumption of fruits, vegetables, starches and dairy foods (times per week) was calculated. To judge the students' ability to understand their weight status and possible actions being taken they were asked "what are you trying to do about your weight" and this was scored as: doing nothing about weight, trying to lose weight or trying gain weight. Students were asked about their athletic ability in comparison to other students of their age and they rated themselves on a scale as: excellent, good, fair or poor. The physical activity questionnaire was adapted from the Youth Physical Activity Survey questionnaire of the School Health Action, Planning and Evaluation System (SHAPES) study [18]. The questionnaire was translated into the principal local language and was pretested and simplified.

To determine the prevalence of overweight and obesity among the students weight and height were measured using calibrated electronic scales and a heightometer. Weight was measured to nearest $\mathrm{kg}$ and height to the nearest $\mathrm{cm}$. WHO age- and sex-specific growth reference charts were used as cut-off points and $\geq 85$ th and $\geq 95$ th percentile (BMI $\mathrm{kg} /$ height $^{2}$ ) was considered equivalent to overweight and obesity respectively. The prevalence of underweight was not assessed as undernutrition was not the focus of this study.

Any potential bias in the study was minimized through training of data collectors on height and weight measurement tools and questionnaire administration without any probing.

\section{Data analysis}

The dependent variable was dichotomous, i.e. overweight and/or obese versus normal weight. Data was entered to Epi-data, version 3.1 and the analysis was performed using SPSS, version 16.0. Descriptive analysis was run to calculate means and standard deviations (SD) for continuous variables. Proportions were calculated for categorical variables such as level of education of parents, sex and type of school. Univariate logistic regression analysis was done followed by the multivariate logistic regression analysis. For associations multiple logistic regression analysis was run to adjust for confounders.

\section{Results}

Data were available for 501 children (255 boys and 246 girls); 3 data sheets were incomplete and were excluded from the analysis. Table 1 shows the frequency of the main sociodemographic variables. The mean age was 13.8 (SD 1.6) years.

A total of 58 students (12\%) were obese and $40(8 \%)$ were overweight according to WHO age and sex-specific cut-offs. Figure 1 shows that more boys than girls were obese ( $15 \%$ versus $8 \%$ ) and similar proportions were overweight (both 8\%).

Results of the univariate analysis showed that there were no statistically significant differences in the rates of obesity comparing students in private and government schools $(P=0.548)$, students who did and did not participate in games outside school $(P=$ 0.552 ) and students who did and did not participate in games in school $(P=$ 0.170).. Those who were eating at fast food outlets rather than at home were significantly more likely to be obese $(P=0.007)$. Children aged $12+$ years were less likely to be obese compared

\begin{tabular}{|c|c|c|}
\hline Variable & No. & $\%$ \\
\hline \multicolumn{3}{|l|}{ Sex } \\
\hline Male & 255 & 50.9 \\
\hline Female & 246 & 49.1 \\
\hline \multicolumn{3}{|l|}{ Mother tongue } \\
\hline Sindhi & 407 & 81.0 \\
\hline Siraiki & 59 & 12.0 \\
\hline Urdu & 20 & 4.0 \\
\hline Balochi & 15 & 3.0 \\
\hline \multicolumn{3}{|c|}{ Socioeconomic status $(n=370)$} \\
\hline Lower tertile & 123 & 32.8 \\
\hline Middle tertile & 124 & 33.1 \\
\hline Upper tertile & 123 & 34.1 \\
\hline \multicolumn{3}{|l|}{ Type of school } \\
\hline Private & 399 & 79.6 \\
\hline Government & 102 & 20.4 \\
\hline \multicolumn{3}{|l|}{ Class grade } \\
\hline 6 & 101 & 20.2 \\
\hline 7 & 105 & 21.0 \\
\hline 8 & 104 & 20.8 \\
\hline 9 & 103 & 20.6 \\
\hline 10 & 88 & 17.6 \\
\hline
\end{tabular}


with those in the lower age bracket $(P$ $=0.053$ ).

\section{Multivariate analysis}

The results of the multivariate analysis after adjusting for age, sex and socioeconomic status are summarized in the Table 2. Normal weight was kept as the reference category.

Independent variables that were significant on the univariate analysis but were not statistically significant on multivariate analysis are not shown on the table: school gives awards in noncompetitive sports $(P=0.123)$; ate lunch at a restaurant in last week $(P=$ $0.22)$; and food frequency variables, specifically dairy foods $(P=0.21)$, starch $(P=0.846)$ and vegetables $(P=0.095)$.

Boys showed a higher risk of obesity compared with girls and this significant relationship was retained in the multivariate model. Specifically, girls were $67 \%$ less likely to be obese than boys $(\mathrm{OR}=0.33)$. Also those in the older age groups were more protected against obesity than those in the younger age groups. For instance, those in the $14.5-15.3$ year age range were $82 \%$ $(\mathrm{OR}=0.18)$ less obese than those in the 9.4-12.2 year age range. However, these data were borderline insignificant for the age variable $(P=0.061)$. Those in the middle socioeconomic status tertile were 3.43 times more likely to be obese than those in the lower tertile $(P$ $=0.004$ ).

Similar to the univariate analysis the multivariate analysis showed that those who wanted to lose weight were 7.75 times more likely to be overweight or obese than those who wanted to gain weight, stay with the same weight or did not do anything about their weight. The results for this were highly significant $(P$ $<0.001)$. Those who rated themselves poor in athletic ability were 5.50 times $(P<0.001)$ more likely to be obese. Finally, those who were eating fruit $\geq 4$ times a week were $55 \%$ (OR 0.45) less likely to be obese than those who ate $<4$ times a week $(P=0.02)$.

\section{Discussion}

A high prevalence of overweight and obesity among the study sample ( $8 \%$ and $12 \%$ respectively) was an important finding of our study. The prevalence of obesity was higher among boys than girls ( $15 \%$ and $8 \%$ respectively). The high prevalence of overweight and obesity was found among this sample of Pakistani children clearly shows that the childhood obesity epidemic is becoming evident in our country. As the study sample was taken from a typical and developed urban setting of one of the largest cities of Pakistan the findings of the study can be generalized to similar population groups.

This prevalence of obesity among these schoolchildren is consistent with, or even higher than, similar studies in other regions of the world. For instance the prevalence of obesity among Turkish children in the Netherlands aged $3-16$ years was $13.1 \%$ and $10.7 \%$ among boys and girls respectively [19]. In a study in Vietnam the prevalence of overweight and obesity was estimated to be $20.5 \%$ and $16.3 \%$ respectively and these figures are similar to ours [20]. In most of these studies the boys were more likely to be overweight and obese than girls. The higher risk of overweight and obesity in boys in our study was retained in the multivariate model and the relationship was highly statistically significant. Boys in Pakistan are likely to have more access to different types of foods outside the home and have more opportunities for exercise, play and recreation, whereas girls suffer from restrictions of social mobility in our society as they grow older.

In developing countries overweight and obesity is increasingly a

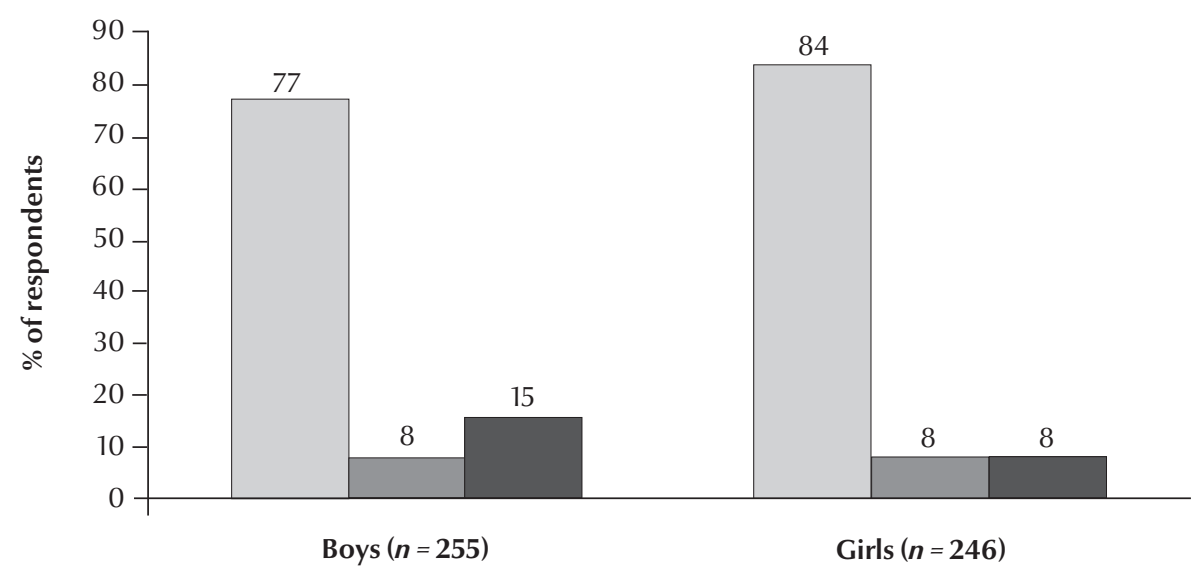

Figure 1 Rates of overweight and obesity (WHO age-and sex-specific categories) for boys and girls in classes 6-10 of public and private schools in Hyderabad 


\begin{tabular}{|c|c|c|c|}
\hline Variable & Crude OR $(95 \% \mathrm{CI})$ & Adjusted OR (95\% CI) & $P$-value \\
\hline \multicolumn{4}{|l|}{ Sex } \\
\hline Male & 1.00 & 1.00 & \\
\hline Female & $0.65(0.41-1.01)$ & $0.33(0.16-0.68)$ & 0.002 \\
\hline \multicolumn{4}{|l|}{ 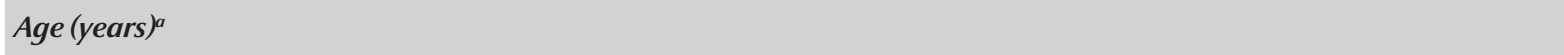 } \\
\hline $9.4-12.2$ & 1.00 & 1.00 & 0.061 \\
\hline $12.3-13.3$ & $0.63(0.32-1.22)$ & $0.47(0.17-1.27)$ & \\
\hline $13.4-14.5$ & $0.43(0.22-0.87)$ & $0.45(0.16-1.27)$ & \\
\hline $14.6-15.3$ & $0.40(0.20-0.83)$ & $0.18(0.05-0.56)$ & \\
\hline $15.4-17.6$ & $0.80(0.42-1.52)$ & $0.60(0.21-1.67)$ & \\
\hline \multicolumn{4}{|l|}{ Socioeconomic status } \\
\hline Lower tertile & 1.00 & 1.00 & 0.004 \\
\hline Middle tertile & $2.22(1.14-4.33)$ & $3.43(1.49-7.93)$ & \\
\hline Upper tertile & $1.62(0.81-3.22)$ & $0.12(0.01-1.00)$ & \\
\hline \multicolumn{4}{|l|}{ Efforts to control weight } \\
\hline Doing nothing about weight & 1.00 & 1.00 & $<0.001$ \\
\hline Trying to lose weight & $4.92(2.69-9.00)$ & $7.75(3.70-16.2)$ & \\
\hline Trying gain weight & $0.12(0.01-0.97)$ & $0.12(0.16-1.00)$ & \\
\hline \multicolumn{4}{|l|}{ Athletic ability } \\
\hline Excellent & 1.00 & 1.00 & $<0.001$ \\
\hline Good & $1.14(0.64-2.03)$ & $1.20(0.53-2.70)$ & \\
\hline Fair & $0.62(0.29-1.31)$ & $0.48(0.16-1.44)$ & \\
\hline Poor & $4.61(2.21-9.61)$ & $5.50(1.81-16.7)$ & \\
\hline \multicolumn{4}{|c|}{ Fruit consumption (times per week) } \\
\hline$<4$ & 1.00 & 1.00 & \\
\hline$\geq 4$ & $2.00(1.27-3.14)$ & $0.45(0.22-0.91)$ & 0.02 \\
\hline
\end{tabular}

$O R=$ odds ratio $; C I=$ confidence interval.

${ }^{a}$ Decimal points are months.

phenomenon among affluent and mostly urban societies. For instance, a recent publication from India using data from the National Family Health Surveys (1992 to 2006) showed that those in the higher income classes were more likely to be obese than those in the lower income groups [21]. In our study children in the middle socioeconomic tertile were 3.43 times more likely to be obese than those in the lower tertile. On the other hand, the upper tertile was less likely to be obese than the lower tertile. A possible explanation for the occurrence of the high prevalence of obesity among the middle income group and absence of obesity among the children belonging to the lower and upper income class is that the lower income group has minimal purchasing power as far as fast-foods particularly energy-dense foods is concerned, while the upper social classes may be more aware of the role of diet and the physical activity and remaining fit.

Studies show that children with higher than normal BMI are more likely to have low self-esteem and less satisfaction with their bodies as well as with their academic achievement [22]. The results of our study also showed a similar trend. For instance, children who rated themselves as poor athletes were 5.50 times more likely to be obese than those who rated themselves excellent athletes. We also showed that children trying to lose weight were 7.75 times more likely to be obese. Other studies have shown that obese children are more aware of their weight status and a high proportion of them wanted or attempted to lose weight $[23,24]$.

As far as diet is concerned data from our multivariate model agrees with other scientific evidence that diet, in this case intake of fruit, protects against obesity [25]. The dietary intake data showed that students who ate fruit more than 4 times a week were $55 \%$ less likely to be obese than those who did not.

\section{Conclusions}

This study provides further evidence of the increasingly high burden of overweight and obesity among children 
living in an urban area of Pakistan. Obesity prevalence was highest among boys, children belonging to middle-income families and those in the younger age groups. The determinants of obesity may lie within the home and school environment. Children who were poor in sports and those who wanted to lose weight were significantly more likely to be obese, indicating that there is an unmet need as far as sports opportunities is concerned. Finally, the consumption of fruits was associated with protection against obesity and may be an indicator of healthier eating in daily life. Parents, schools, education department, urban planners and other stakeholders need to take steps to promote physical activity and healthy eating among schoolage children in Pakistan.

\section{Acknowledgements}

We thank Dr Zafar Fami, Associate Professor and Dr Romaina Iqbal
Assistant Professor, Department of Community Health Sciences at The Aga Khan University, Karachi, for their help and support in the study. The study received funding from the Department of Community Health Sciences, The Aga Khan University for the first author's FCPS in Community Medicine dissertation. The dissertation is already accepted for the FCPS part II examination by the College of Physicians and Surgeons Pakistan.

\section{References}

1. Childhood overweight and obesity. World Health Organization [website]. (http://www.who.int/dietphysicalactivity/childhood/en/, accessed 17 December 2012).

2. Figueroa-Colon R et al. Prevalence of obesity with increased blood pressure in elementary school-aged children. Southern Medical Journal, 1997, 90:806-813.

3. Costa RF, Cintra IP, Fisberg M. Prevalência de sobrepeso e obesidade em escolares da cidade de Santos, SP. [Prevalence of overweight and obesity in school children of Santos city, Brazil]. Arquivos Brasileiros de Endocrinologia e Metabologia, 2006, 50:60-67.

4. Kapil U et al. Prevalence of obesity amongst affluent adolescent school children in delhi. Indian Pediatrics, 2002, 39:449-452.

5. Akatsu H, Aslam A. Prevalence of hypertension and obesity among women over age 25 in a low income area in Karachi, Pakistan. Journal of the Pakistan Medical Association, 1996, 46:191-193.

6. Jafar TH et al. Ethnic differences and determinants of diabetes and central obesity among South Asians of Pakistan. Diabetic Medicine, 2004, 21:716-723.

7. Afzal MN, Naveed M. Childhood obesity and Pakistan. Journal of the College of Physicians and Surgeons-Pakistan, 2004, 14:189-192.

8. Jafar TH, Hatcher J, Bhutta ZA. Rapidly rising rates of overweight and obesity coupled with persistently high rates of undernutrition among school aged children in an urban IndoAsian population: authors' response. Archives of Disease in Childhood, 2008, 93:1000-1001.

9. Aziz $\mathrm{S}$ et al. Prevalence of overweight and obesity among children and adolescents of affluent schools in Karachi. Journal of the Pakistan Medical Association, 2009, 59:35-38.

10. Warraich $\mathrm{HJ}$ et al. Prevalence of obesity in school-going children of Karachi. PLoS ONE, 2009, 4:e4816.

11. International Association for the Study of Obesity [website] (www.iaso.org/, accessed 31 December 2012).

12. Pappas G et al. Health status of the Pakistani population: a health profile and comparison with the United States. American Journal of Public Health, 2001, 91:93-98.

13. McCormack GR et al. Associations between familial affluence and obesity risk behaviours among children. Paediatrics and Child Health, 2011, 16:19-24.
14. Andegiorgish AK et al. Prevalence of overweight, obesity, and associated risk factors among school children and adolescents in Tianjin, China. European Journal of Pediatrics, 2012, 171(4):697-703.

15. Anderson SE, Whitaker RC. Attachment security and obesity in US preschool-aged children. Archives of Pediatrics and Adolescent Medicine, 2011, 165(3):235-242.

16. Beyerlein A et al. Genetic markers of obesity risk: stronger associations with body composition in overweight compared to normal-weight children. PLOS ONE, 2011, 6:e19057.

17. Al-Saeed WY et al. Prevalence and socioeconomic risk factors of obesity among urban female students in Al-Khobar city, Eastern Saudi Arabia, 2003. Obesity Reviews, 2007, 8:93-99.

18. School Health Action, Planning and Evaluation System [website] (http://www.shapes.uwaterloo.ca, accessed 9 January 2013).

19. De Wilde JA et al. Trends in overweight and obesity prevalence in Dutch, Turkish, Moroccan and Surinamese South Asian children in the Netherlands. Archives of Disease in Childhood, 2009, 94:795-800.

20. Dieu HT et al. Prevalence of overweight and obesity in preschool children and associated socio-demographic factors in Ho Chi Minh City, Vietnam. International Journal of Pediatric Obesity, 2007, 2:40-50.

21. Wang $\mathrm{Y}$ et al. Is obesity becoming a public health problem in India? Examine the shift from under- to overnutrition problems over time. Obesity Reviews, 2009, 10:456-474.

22. Kamtsios S, Digelidis N. Physical activity levels, exercise attitudes, self-perceptions and BMI type of 11 to 12-year-old children. Journal of Child Health Care, 2008, 12:232-240.

23. Stevens J et al. Weight-related attitudes and behaviors in fourth grade American Indian children. Obesity Research, 1999, 7:34-42.

24. Gusella J, Goodwin J, van Roosmalen E. 'I want to lose weight': early risk for disordered eating? Paediatrics and Child Health, 2008, 13:105-110.

25. Kubik MY, Lytle L, Fulkerson JA. Fruits, vegetables, and football: findings from focus groups with alternative high school students regarding eating and physical activity. Journal of Adolescent Health, 2005, 36:494-500. 